\title{
Effect of thermocycling on the microstructure of Ti-6Al-4V alloy in simulated low Earth orbit space environment
}

\author{
Peng Lv*, Jingbo Xu, Ruoran Yang, Conglin Zhang, Futao Zhang, Shuheng Dong and Qingfeng Guan
}

\begin{abstract}
The study of material damage and its physical mechanisms, the deep understanding of material performance degradation processes, and the improvement of key materials and devices used in a space environment are undoubtedly of critical scientific importance. This work investigated the mechanical properties and microstructures of the Ti-6Al-4V alloy subjected to thermocycling in a simulated low Earth orbit (LEO) space environment by using microhardness tests, $\mathrm{X}$-ray diffraction, scanning electron microscopy, and transmission electron microscopy. The results revealed an initial increase in hardness with the number of cycles, followed by a subsequent decrease. After 300 thermal cycles, many cavities were formed at the two-phase interface of the Ti-6Al-4V alloy. The dominating structures were transformed into dislocation cell substructures of larger size. After 500 cycles, the central structures in the sample were subgrains evolving by dislocation cells, as well as intragranular twins and jogs structures. The relationship between microstructural evolution and thermal fatigue in LEO space environment was discussed, which may help predict the fatigue damage of materials.
\end{abstract}

Keywords: thermocycling, Ti-6Al-4V alloy, microstructure, fatigue damage

\section{INTRODUCTION}

Owing to its low density, high specific strength, strong corrosion resistance, high toughness, and good high-temperature properties, the $\mathrm{Ti}-6 \mathrm{Al}-4 \mathrm{~V}$ alloy has been widely used as structural material in space vehicles [1-4]. During a long period of service in space, mostly in the low Earth orbit (LEO) space environment, the Ti-6Al-4V alloys are subjected to severe thermal cycles (approximately between -110 and $140^{\circ} \mathrm{C}$ ), withstanding great temperature differences during the day-night cycle (intervals of $90 \mathrm{~min}$ ) [5-6]. Rapid temperature changes combined with large temperature gradients inside the materials can induce the thermal fatigue (TF) loading, which has a crucial effect on the stress state and mechanical properties of the materials [7-8]. Thus, after prolonged use in LEO space, TF may induce fracture failure of the components. Therefore, TF is an important phenomenon for the aeronautical materials serving in the LEO environment.

To understand the effect of TF damage in the LEO space environment, it is necessary to investigate the microstructural evolutions of the samples subjected to the thermal cycles. As in-flight experiments are expensive and time-consuming, ground simulations have been widely performed to verify the effects of the LEO environment [9]. However, during the course of the simulated LEO thermal cycling (from -110 to $140^{\circ} \mathrm{C}$, which is difficult to control), the variation of the alloy structure may be still very slow. Therefore, the initial structure must heavily affect the subsequent behavior of the alloy. In this study, the effects of thermocycling on the microstructure of the Ti-6Al-4V alloy in the temperature range from $-197^{\circ} \mathrm{C}$ (temperature of liquid nitrogen) to $200^{\circ} \mathrm{C}$ were investigated. Here, we focused on the relationships between microstructure and hardness of the Ti-6Al-4V alloy subjected to the thermal cycles. The results of this work will be beneficial for understanding the mechanism of TF damage in the LEO space environment.

\section{EXPERIMENTAL METHODS}

The Ti-6Al-4V alloy, investigated in this study, has a nominal chemical composition of (wt.\%) $6.28 \mathrm{Al}, 3.97 \mathrm{~V}, 0.18 \mathrm{O}$, $0.052 \mathrm{Fe}, 0.0062 \mathrm{~N}, 0.008 \mathrm{C}$, and balanced Ti. The shapes and dimensions of the specimens used for cycle fatigue testing are shown in Fig. 1a. To simulate the temperature changes of the spacecraft surface, all specimens subjected 
$\mathbf{a}$
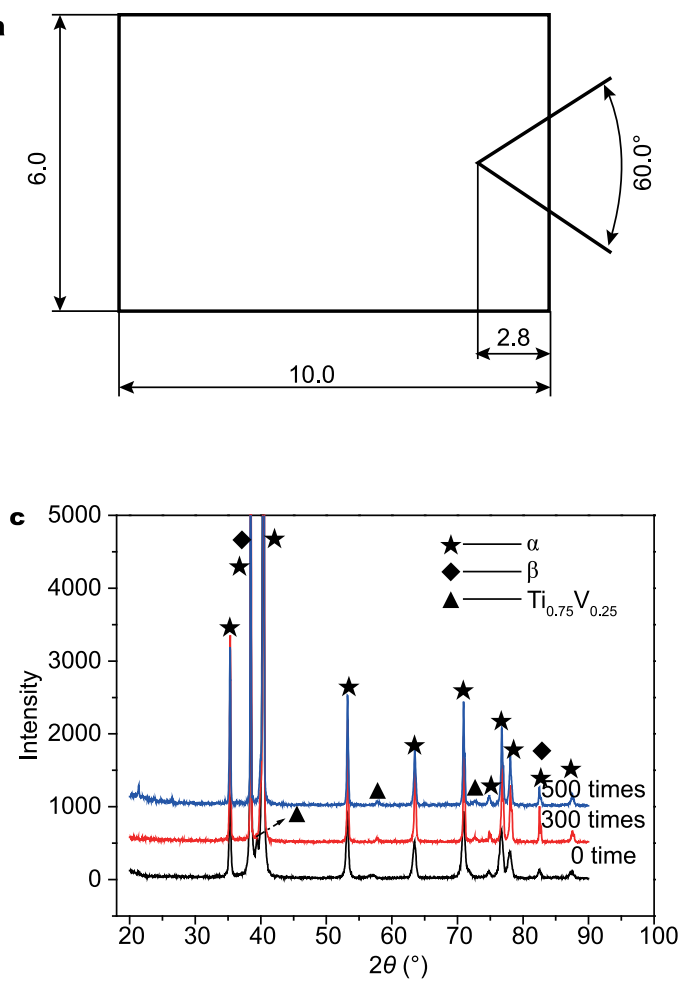

b

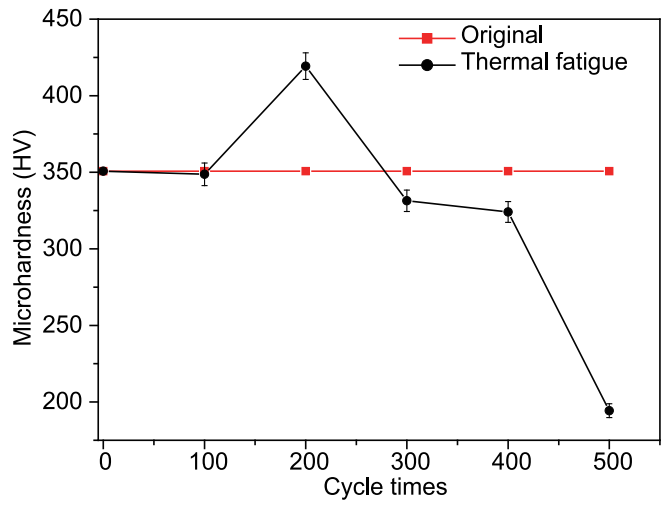

d

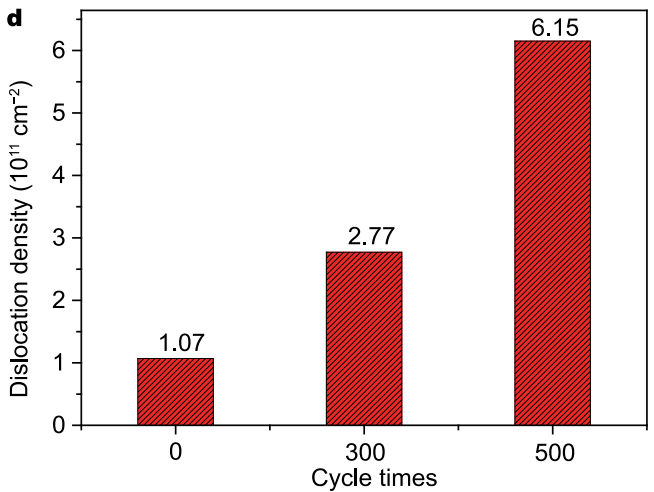

Figure 1 (a) Size and shape of the sample for cycle fatigue testing (dimensions in $\mathrm{mm}$ ); effect of thermocycling on (b) microhardness, (c) XRD patterns and (d) dislocation density of the Ti-6Al-4V alloy.

to thermal fatigue tests were treated by using a GSL1300X vacuum tube type furnace in $\mathrm{Ar}$ atmosphere for $10 \mathrm{~min}$ at $200^{\circ} \mathrm{C}$, and then cooled quickly in liquid nitrogen $\left(-197^{\circ} \mathrm{C}\right)$.

The microstructural characterization of the specimens was comprehensively performed by using transmission electron microscopy (TEM; JEOL-2100) and scanning electron microscopy (SEM; JEOL-JSM-7001F). To identify the phases, X-ray diffraction (XRD; Rigaku D/max-2500/pc) was conducted with $\mathrm{CuKa}$ radiation at $35 \mathrm{kV}$ and $25 \mathrm{~mA}$ in a continuous scanning mode $\left(0.2^{\circ} \mathrm{min}^{-1}\right)$. Vickers hardness measurements were performed by applying a load of $0.98 \mathrm{~N}$ for $15 \mathrm{~s}$ on the selected specimens to evaluate the mechanical properties after the thermocycling experiments. For the TEM analysis, samples were sliced from the specimens by using a low-speed diamond saw; they were then polished, dimpled, and twin-jet electropolished. The electrolyte was comprised of $6 \%$ perchloric acid, $36 \%$ butanol, and $60 \%$ carbinol.

\section{RESULTS AND DISCUSSION}

The microhardness of the Ti- $6 \mathrm{Al}-4 \mathrm{~V}$ alloy as a function of the number of thermal cycles is shown in Fig. 1b. No significant change in microhardness is observed in the tested sample after 100 thermal cycles. However, a remarkable increase can be seen between 100 and 200 cycles; notably, the microhardness reaches its maximal value at 200 cycles, considerably exceeding its original value. After 200 cycles, the hardness decreases by increasing the number of thermal cycles. Additionally, the softening rate is higher between 200 and 300 cycles, and between 400 and 500 cycles. These results reveal that, after thermocycling in a simulated LEO space environment, the Ti-6Al-4V alloy exhibits clear cyclic softening.

The XRD patterns of the Ti-6Al-4V specimens subjected to thermocycling are shown in Fig. 1c. All samples consist of $\alpha$ and $\beta$ phases. After 500 thermal cycles, the Ti- $6 \mathrm{Al}-4 \mathrm{~V}$ alloy is mainly comprised of a phase. After Stokes [10] deconvolution, the physical broadened profile and its corresponding Fourier coefficients $A(L)$ were obtained; the two components, i.e., the "particle" coefficient $A^{\mathrm{P}}(L)$ and "strain" coefficient $A^{\mathrm{S}}(L)$, were then separated according to: [11]

$$
\begin{gathered}
A^{\mathrm{P}}(L)=a-\frac{L}{D_{\text {eff }},} \\
A^{\mathrm{S}}(L)=\exp \left(-2 \beta_{0} L-\pi \beta_{\mathrm{g}}^{2} L^{2}\right),
\end{gathered}
$$


where $a$ is a quantity expressing the "hook" effect, $L$ is the specific length perpendicular to the reflecting planes, $D_{\text {eff }}$ is the average "effective" coherent domain size, and $\beta_{\mathrm{c}}$ and $\beta_{g}$ are the Cauchy and Gaussian widths of the strain-broadened profile, respectively. By applying the standard curves and procedures described in $[11,12]$, the average dislocation density $\rho$ and configuration parameter $M$ were obtained. The stored elastic energy density $E / V$ was then directly obtained by:

$$
\frac{E}{V}=A G \rho b^{2} \ln \frac{M}{r_{0}(Q)^{1 / 2}},
$$
$1 / 4 \pi(1-v)$ for edge dislocations, $v$ is the Poisson's ratio, $G$ is the shear modulus, $B$ is the dislocation strength, and $r_{0}$ is the dislocation nucleus radius. Based on the XRD data, $(E / V)^{111}$ was calculated by Equation (3), and thus the average dislocation density after thermal cycles was estimated. As shown in Fig. 1d, the dislocation density increased with the number of thermal cycles.

Fig. 2 shows the SEM images of the Ti-6Al-4V alloy before and after thermal cycling. Fig. 2a shows the typical bimodal microstructure of the Ti- $6 \mathrm{Al}-4 \mathrm{~V}$ alloy in the orig- where $A$ is equal to $1 / 4 \pi$ for screw dislocations and

inal sample. The initial structure consisted of a mixture of lath-structure $\alpha$ phase and intergranular $\beta$ phase in an $\alpha$ phase matrix. In this micrograph, the dark regions indicate the $\alpha$ phase, while the white regions represent the $\beta$ phase; the latter were distributed almost continuously along the boundary of the a phase. After 300 cycles, as shown in Fig. $2 \mathrm{~b}$, the primary a phase fraction clearly increases, showing some elongation. Moreover, a large quantity of cavities appear at the two-phase interface, as indicated by the arrows in the enlarged image in the inset of Fig. 2b. Fig. 2c clearly shows the morphology of the sample after $500 \mathrm{cy}-$ cles of thermal cycling. The long strips of a grains were significantly reduced, and the $\alpha$ phase acquired a rounded structure. In addition, the continuity of the $\beta$ phase in the $\alpha$-phase grain boundaries degraded. The number of cavities at the two-phase interface increased remarkably after 500 cycles, as indicated by the arrows in Fig. 2 d. The average size (diameter) of the cavities was estimated to be $\sim 0.6$ $\mu \mathrm{m}$ from the images shown in Fig. $2 \mathrm{~b}$, but it increased to $0.9 \mu \mathrm{m}$ after 500 cycles (Fig. 2(c)). Moreover, the density of the cavities increased from $1.85 \times 10^{13}$ to over $9.26 \times 10^{13}$ $\mathrm{cm}^{-2}$.
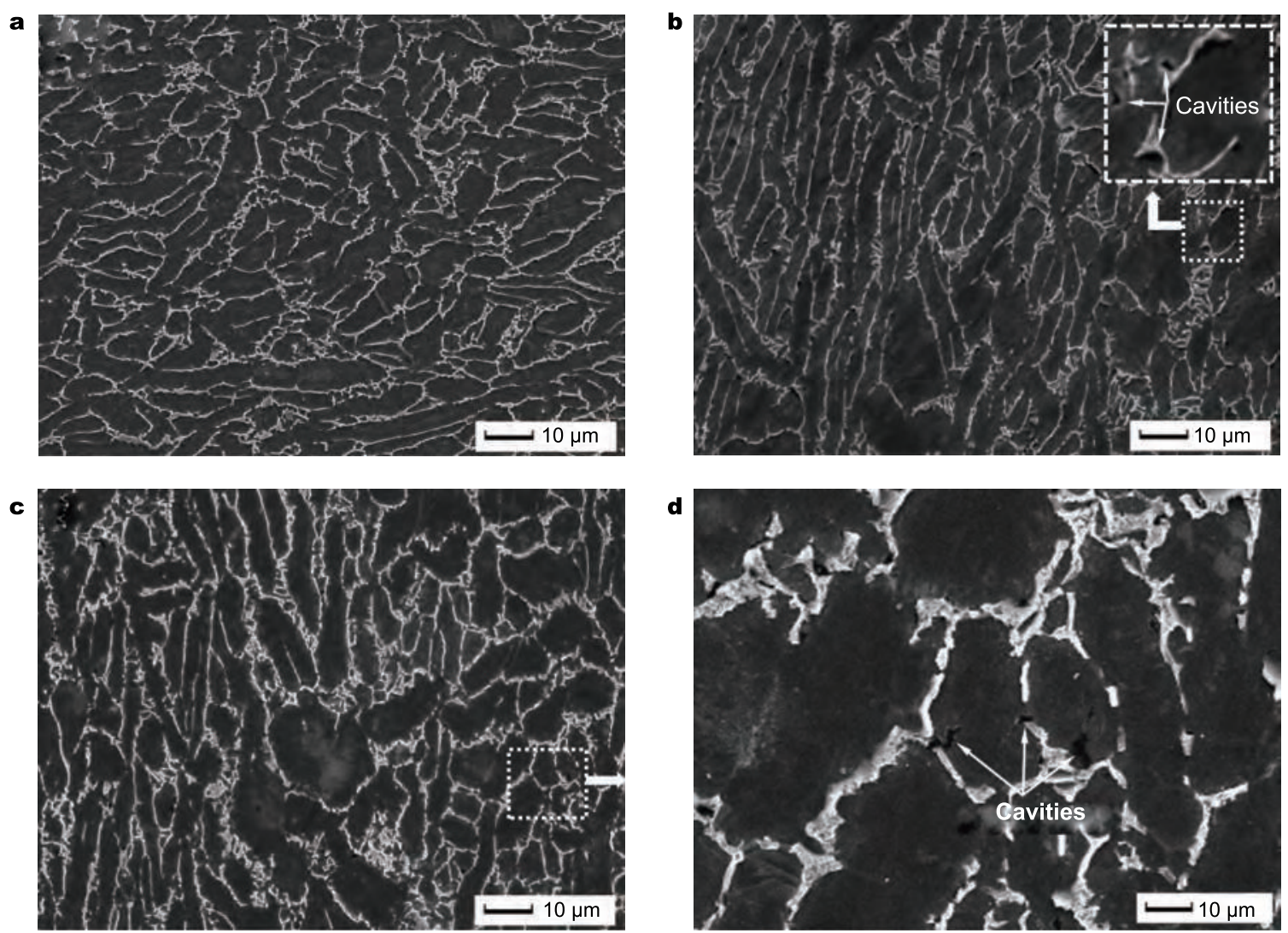

Figure 2 SEM images of TI-6AL-4V alloy after thermal cycles: (a) original sample; (b) after 300 thermal cycles; (c) and (d) after 500 thermal cycles. 
Cavity formation and crack initiation are common phenomena that often appear on the surface layer upon plastic deformation. Generally, the initial materials have no cracks before the fatigue fracture occurs. Two processes then happen: one is the initiation of microcrack or cavities; the other involves the crack propagation or cavity growth. In addition, most material failures occurring on the surfaces (fatigue fracture, fretting fatigue, wear and corrosion, etc.) are very sensitive to the surface structure and properties [13]. Fatigue fracture is preferentially initiated at near-surface cavities and interdendritic cavities, so that surface optimization may effectively enhance the overall properties of the materials. The number, size, and location of the cavities are crucial parameters, as they have strong influence on the fatigue life. The shape of the cavities can affect the fatigue crack initiation. Fatigue microcracks usually initiate at shrinkage cavities with sharp radii, and the dispersibility of the fatigue performance increases because of the presence of cavities. The experimental results in Fig. 1d indicate that, when the softening phenomenon caused by thermal cycling occurs, the cavities are likely to initiate near the grain boundary. Thus, the number and size of cavities increase dramatically with the increase in the number of cycles.

Fig. 3 shows the TEM images of the Ti-6Al-4V alloy after 200 thermal cycles. The main dislocation patterns were heavy dislocation tangles, and the dislocation density greatly increased with the number of cycles. In addition, a few dislocation cells were also formed in other areas. The size of the cell wall was small $(0.5 \mu \mathrm{m})$, but the wall of the dislocation cell was thick. The shape and size of the cells were not uniform, as shown in Fig. 3a. Thus, the apparent transformation of the dislocation patterns was more pronounced after 200 cycles. Between 100 and 200 cycles, the Ti-6Al-4V alloys were deformed, and the dislo- cations moved. Therefore, grain boundaries and dislocation density increased rapidly and simultaneously, owing to the generation of new dislocations. When the dislocation growth reached a certain degree, the dislocation lines entangled with each other, which led to difficulties in movement of dislocation lines, the dislocation motion resistance increased, showing hardening characteristics. Considerable black extinction contours, which were induced by the internal stress, were also observed in the samples after 200 thermal cycles (Fig. 3 b). On one hand, this indicated that internal residual stress of high amplitude appeared in the sample after a certain number of thermal cycles. On the other hand, it also suggested that the thermal cycling process caused internal plastic deformation [14]. Notably, the initiation of microcracks and brittle fractures is likely to occur in stress concentration areas, leading to the degradation of the mechanical properties.

The plastic deformation of a metal is accompanied by the evolution of the dislocation structures. After 200 cycles, according to the dislocation patterns, the dislocation tangles irregularly emerged. The dislocation patterns are mainly composed of dislocation cells, which are observed after 300 cycles (Fig. 4a). These dislocation cellular structures (dislocation cells, dislocation tangles) were caused by the thermal cycle process, which can lead to the plastic deformation of materials and facilitate the movement of the dislocations. The size of the dislocation cell increased remarkably (1.3 $\mu \mathrm{m})$, but the cell wall was thin, and the orientation on both sides of the cell wall was not clear. Therefore, the dislocation density was significantly reduced, causing the softening of the Ti-6Al-4V alloy. A higher density of small defect clusters (with sizes generally below $10 \mathrm{~nm}$ ) was observed in the Ti-6Al-4V samples after further thermal cycling. Fig. $4 \mathrm{~b}$ shows the typical structure of the black spot defects in the dislocation cells. As there were no precipitated phases
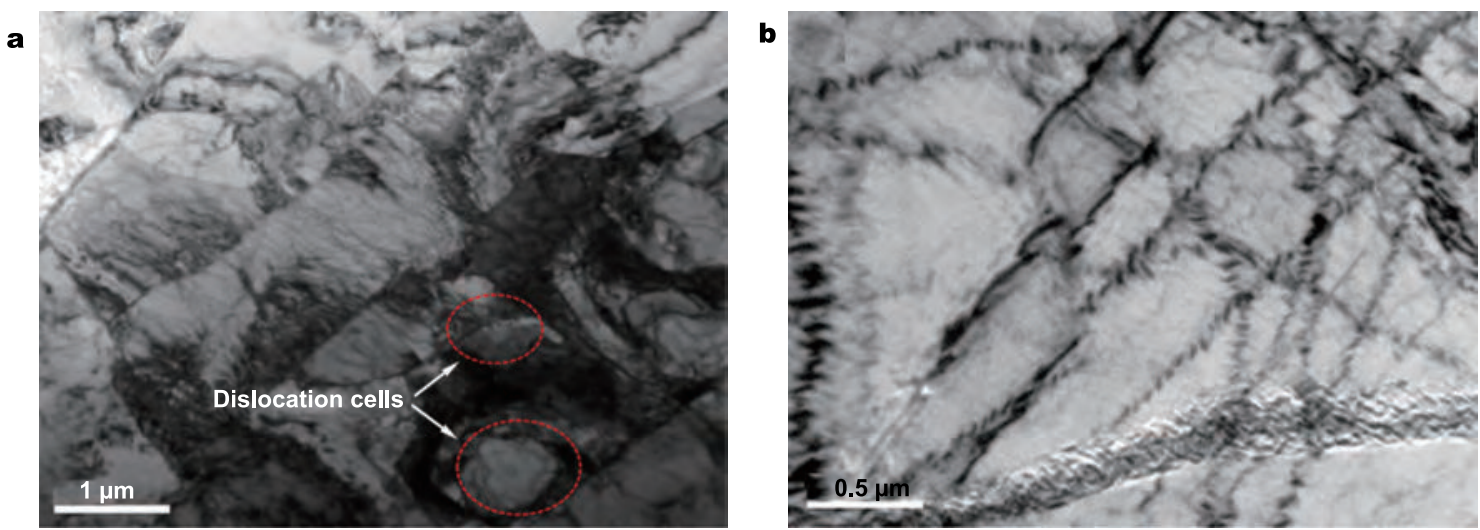

Figure 3 TEM images of Ti-6Al-4V alloy after 200 thermal cycles. 
a

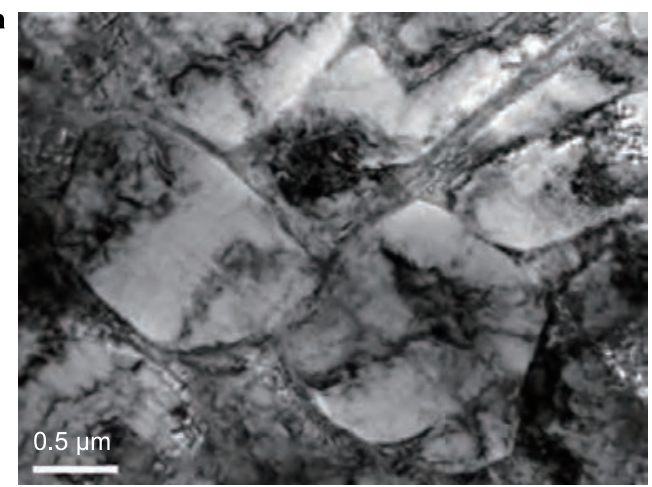

c

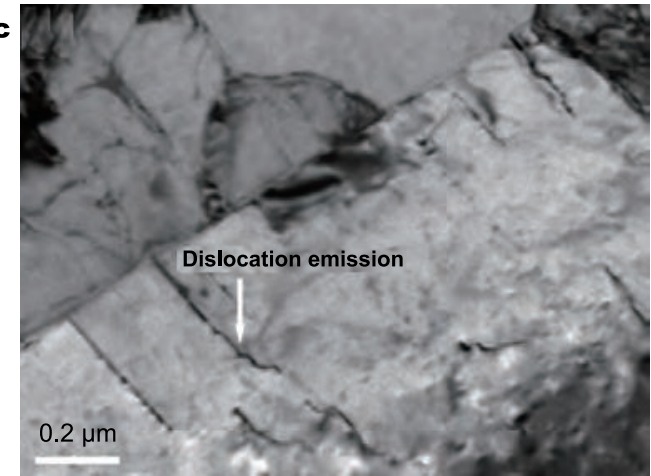

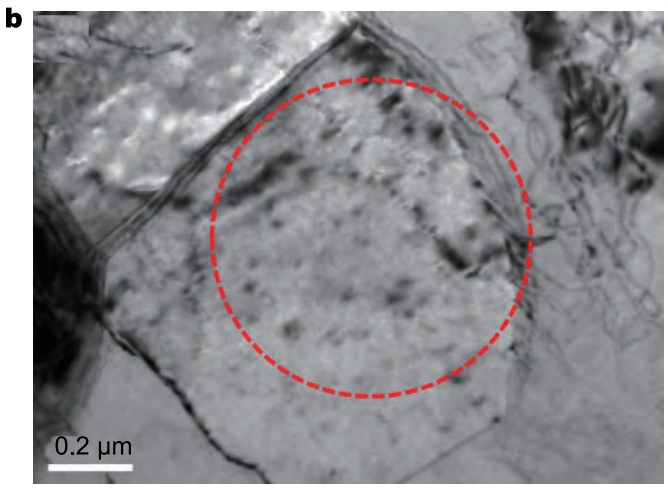

d

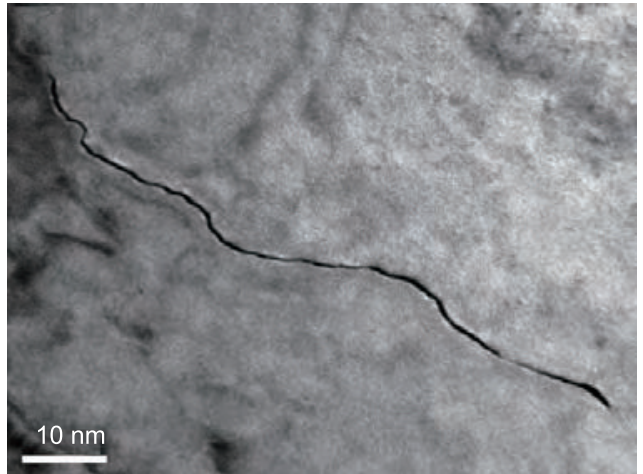

Figure 4 TEM images of Ti-6Al-4V alloy after 300 thermal cycles: (a) dislocation cells; (b) black spot defects; (c) dislocation emission; (d) microcrack.

in TC4 after the thermal cycles, the black points did not comprise other phases. Moreover, according to the results of our previous studies, these black point defects were vacancy cluster defects, which were formed by the aggregation of supersaturated vacancy defects [15]. The thermal cycling process could promote a large number of vacancy defects, which could easily diffuse to the surface of the material during the heating process, causing the formation of cavities on the surface. Notably, for a number of cycles up to 300 , the alloy exhibited significant emission or release of parallel dislocations, as indicated by the arrow in Fig. $4 c$. The dislocations typically emanated from grain boundaries, resulting in deformation stacking faults and twinning $[16,17]$. Repeated thermal cycles can enhance dislocation emission and motion, thus facilitating the nucleation and coalescence of cavities, which can result in brittle fracture at low stress intensities. Dislocation emission from a crack tip has been one of the most fundamental processes for understanding the ductile-brittle behavior in crystalline materials. These dislocation emissions were likely to induce brittleness, and led to brittle microcrack nucleation and propagation. A microcrack was observed along the grain in the specific region shown in Fig. 4d, in good agreement with the above viewpoint. The appearance of microcracks was drastically detrimental to the properties of the material. The fatigue cracks formed as the result of localized plastic deformation during the thermal cycling process. The fatigue cracks nucleated preferentially at $\alpha / \alpha$ or $\alpha / \beta$ boundaries located at the notched root. The presence of second-phase particles also resulted in local stress and strain concentrations, which is considered to favor microcrack initiation. Therefore, the microstructure of the Ti-6Al-4V alloy had a significant influence on the fatigue crack initiation and the incipient crack propagation.

Fig. 5 shows the TEM images of the Ti-6Al-4V alloy after 500 thermal cycles. The dislocation cells transformed into a subgrain structure with an $\alpha$ phase interior, as shown in Fig. 5a. Fig. 5b shows that the boundaries are composed of regular arrays of dislocations, i.e., they were low angle grain boundaries (or sub-boundaries). Simultaneously, subgrains were formed, as indicated by the dash lines. Besides the subgrain structure, twin and jog structures were also formed within the a phase after 500 thermal cycles, as revealed by the TEM observations in Figs $5 \mathrm{c}$ and $\mathrm{d}$. The selected area electron diffraction (SAED) pattern for the twin area (inset of Fig. 5c) confirmed that thermal cycling did not cause the development of a martensitic a phase, but led to the formation of a twin structure [18]. The intense spot in the SAED pattern indicates the TC4 matrix, while the arrowed weak spot (1012) indicates the twin. According 
a

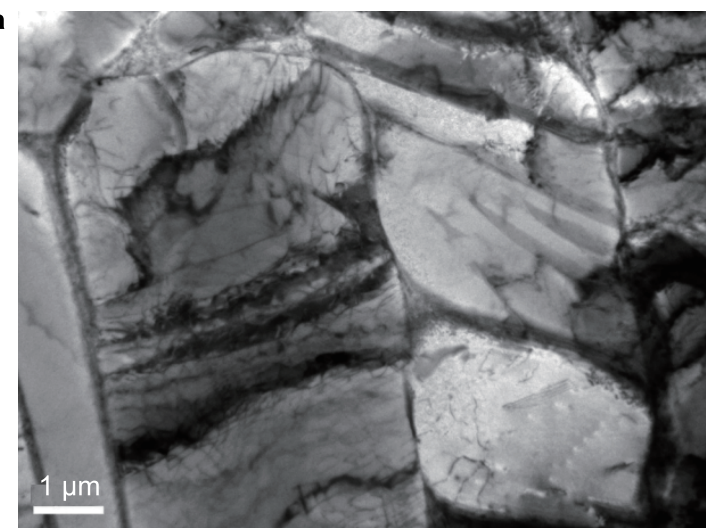

c

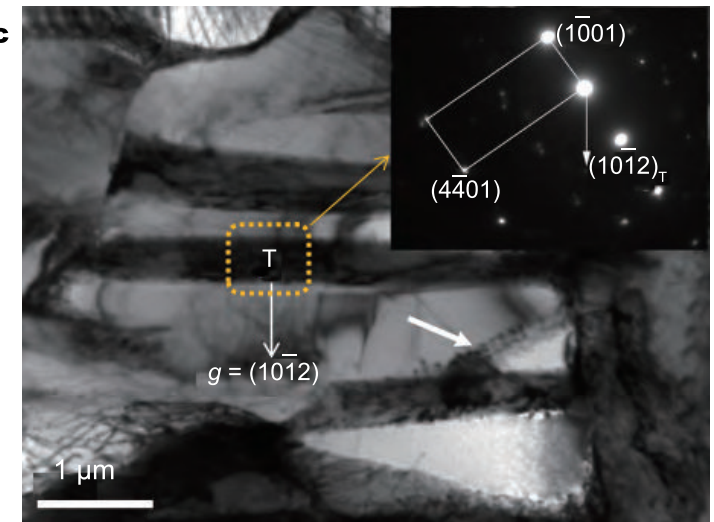

b

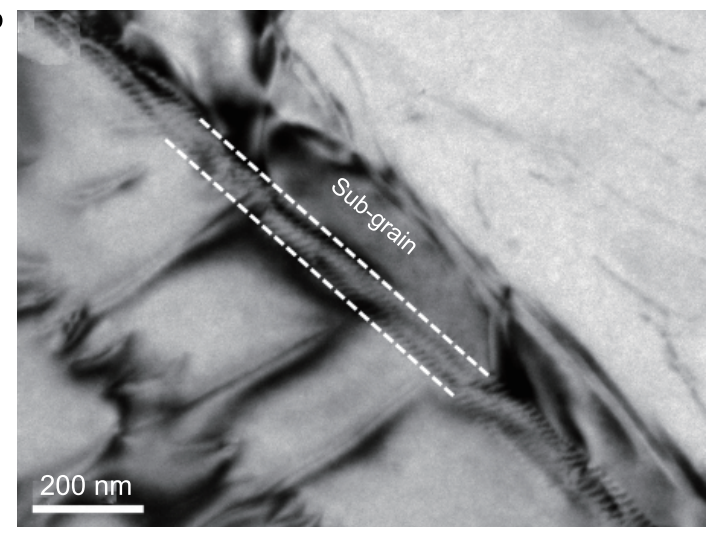

d

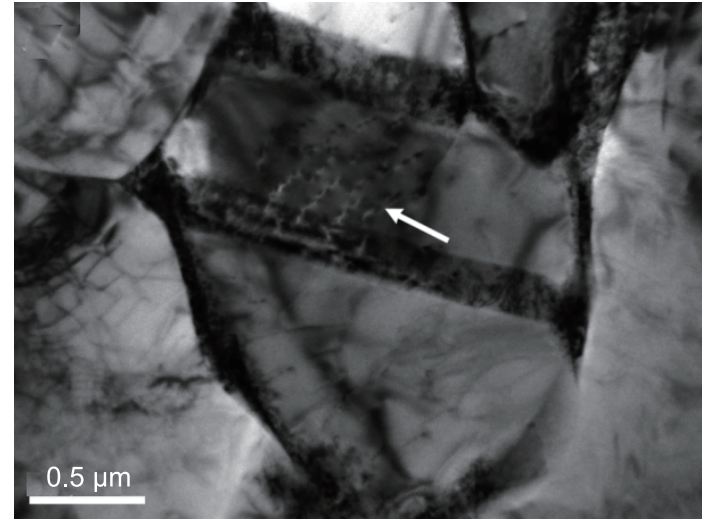

Figure 5 TEM images of Ti-6Al-4V alloy after 500 thermal cycles: (a) dislocation cells; (b) subgrain; (c) twins; (d) jogs.

to the principle of electron diffraction, the reciprocal vector $\mathbf{g}(10 \overline{1} 2)$ was perpendicular to the twin plane, while the crystal plane normal direction was the same as the $\mathbf{g}$ direction. Therefore, the twin plane was (1012), which is the typical twin plane in hcp structures. The twinning direction was [1011]. The twin system was $(10 \overline{1} 2) /[1011]$. Dislocation slipping and twinning are two primary deformation mechanisms. Once dislocation slipping is successfully triggered in the crystal, twinning is correspondingly inhibited, because the stress required for twinning is usually higher than that necessary for slipping. Thus, some hcp metals with limited number of slip systems may preferably twin. During the thermal cycles, the structural change of the twin boundaries was intrinsically related to the change of the internal stress configuration in the individual grains. Moreover, lattice and twinning dislocations could either interact with each other or move towards lamellar boundaries, or deformation twin boundaries, being then pinned by them [19]. These processes may lead to local stress concentrations and formation of various substructures that may play an important role in accelerating effectively the local stress concentration and promoting the formation of microcracks [20]. The morphologies of jogs and twins are similar, but a magnified observation of jog boundaries shows that they are not as straight as the twin boundaries. Many dislocation steps are formed on the boundary, and they are a morphological characteristic of jogs. Notably, a complete row of atoms cannot be removed from, or added to, the extra plane of the edge dislocations. In practice, single vacancies or small vacancy clusters diffuse from or to the dislocation line. The effect is that a short portion of the dislocation line climbs up or down, resulting in the formation of two steps at the dislocation line; these steps are called jogs. Dislocations in metals highly deformed by thermal cycling are expected to contain many jogs, which are primarily formed during intersection with other dislocations. The thermal heating process induces the generation of jogs by absorption or emission of point defects. Both positive and negative climbs can occur by nucleation and motion of jogs; they are sources and sinks for vacancies. This mechanism is thermally induced because it responds to a supersaturation or undersaturation of point defects. At large undersaturations or supersaturations, this process becomes more pronounced.

The results in Figs 5b-d show that subgrain, twin, and jog structures can release parallel dislocations (indicated 
by the arrow), suggesting that these areas can easily become favorable locations for stress concentration. Obviously, these structure factors, caused by the microscopic stress and strain concentrations, become an important source to prompt microcrack initiation. In other words, the sources of microcrack initiation increase rapidly with the number of thermal cycles. On the other hand, because of the local crack tip stress concentration, the crack growth is expected to be facilitated. The increase in microcrack initiation sources increases the probability of interfingering during the microcrack propagation process, leading to the formation of a larger crack and failure of the material. However, for several reasons, including the small size of the TEM experimental observation area and the microcrack random distribution, microcracks were not observed in the TEM experiments after 500 cycles. More detailed experimental observations have been planned and will be conducted in the near future.

\section{CONCLUSIONS}

In this work, the mechanical properties and microstructures of the Ti-6Al-4V alloys subjected to thermocycling in a simulated LEO space environment were investigated. The hardness initially increased with the number of cycles, but then decreased. Grain boundaries easily became favorable locations for stress concentration and microcrack initiation. After 500 cycles, the dislocation cells disappeared, replaced by a subgrain structure, as well as intragranular twins and jogs. Grain boundaries, sub-boundaries, twin boundaries, and jog interfaces were preferred for local stress concentration and microcrack initiation. These results provide useful information for understanding the relationship between microstructural evolution and thermal fatigue, helping predict the material fatigue damage in a simulated LEO space environment.

Received 2 March 2016; accepted 12 May 2016; published online 30 May 2016

1 Li C, Chen JH, Wu X, et al. Effect of heat treatment on microstructure and properties with compression of metastable $\beta$-titanium alloy. Metal Sci Heat Treat, 2014, 56: 245-252

2 Imayev V, Imayev R, Khismatullin T, et al. Superplastic behavior of Ti-43Al-7(Nb,Mo)-0.2B alloy in the cast+heat-treated condition. Scrip Mater, 2007, 57: 193-196

3 Huryn SV, Pohrelyuk IN, Fedirko VN. Carbooxidation of titanium by a gas-phase method from powders. Metal Scie Heat Treat, 2014, 56: $24-32$

4 Gaivoronskii IV, Girzhon VV, Skrebtsov AA, et al. Structure and properties of surface layers of sintered powder titanium VT1-0 after laser treatment. Metal Sci Heat Treat, 2014, 56: 57-59

5 Grossman E, Gouzman I. Space environment effects on polymers in low earth orbit. Nucl Instrum Methods Phy Res, 2003, 208: 48-57

6 Han J H, Kim CG. Low earth orbit space environment simulation and its effects on graphite/epoxy composites. Compos Struct, 2006, 72: $218-226$

7 Guan QF, Jiang QC, Fang JR, et al. Microstructures and thermal fatigue behavior of $\mathrm{Cr}-\mathrm{Ni}$-Mo hot work die steel modified by rare earth. Isij Inter, 2003, 43: 784-789

8 Jiang QC, Sui HL, Guan QF. Thermal fatigue behavior of new type high-Cr cast hot work die steel. ISIJ Inter, 2004, 44: 1103-1107

9 Moon JB, Kim MG, Kim CG, et al. Improvement of tensile properties of CFRP composites under LEO space environment by applying MWNTs and thin-ply. Compos Part A Appl Sci Manuf, 2011, 42: 694-701

10 Stokes AR. Phase-angle determination in X-ray crystallography. Nature, 1948, 161: 679-680

11 Wang YM, Welter GL. Plasma-magnetospheric interaction in X-ray sources-an analysis of the linear Kelvin-Helmholtz instability. Astron Astrophys, 1982, 113: 113-117

12 Tung F, Zwui S, Wang Y. X-ray analysis of microscopic structure in deformed brass. J Mater Sci, 1986, 21: 3223-3226

13 Lawrynowicz Z. Plastic deformation and softening of the surface layer of railway wheel. Adv Mater Sci, 2015, 15: 5-13

14 Williams DB, Carter CB. Transmission Electron Microscopy: A Textbook for Materials Science. Micron Berlin: Springer, 2009, 28

15 Cheng XW, Guan QF, Fan XH, et al. Effect of vacancy defect clusters on the optical property of the aluminium filter used for the space solar telescope. Chin Phys B, 2010, 19: 417-421

16 Gutkin MY, Ovid'Ko IA, Skiba NV. Emission of partial dislocations by grain boundaries in nanocrystalline metals. Phys Solid State, 2004, 46: 2042-2052

17 Terentyev D, Zhurkin EE, Bonny G. Emission of full and partial dislocations from a crack in BCC and FCC metals: an atomistic study. Comput Mater Sci, 2012, 55: 313-321

18 Boyer R, Welsch G, Collings EW. Materials Properties Handbook: Titanium Alloys. Novelty: ASM International, 1994

19 Zhang LC, Chen GL, Ye HQ. Substructures of deformation twins and twin intersections in a Ti-45Al-8Nb-2. $5 \mathrm{Mn}$ alloy heavily deformed at room temperature. Mater Sci Eng A, 2001, 299: 267-274

20 Chai G. Fatigue behaviour of duplex stainless steels in the very high cycle regime. Inter J Fatigue, 2006, 28: 1611-1617

Acknowledgments This work was supported by the Senior Talent Foundation of Jiangsu University (14JDG127), the Postdoctoral Foundation of Jiangsu province (1501159B), the open project program of Key Laboratory of Materials Modification by Laser, Ion and Electron Beams (Dalian University of Technology), and Ministry of Education (LABKF1504).

Author contributions Guan Q conceived the idea of this study. Xu J, Yang R, Zhang F, and Dong $\mathrm{S}$ assisted in designing the method and analyzing the data. Zhang $\mathrm{C}$ prepared the manuscript. Lv P revised the paper and coordinated this work. All authors discussed the results and commented on the manuscript.

Conflict of interest The authors declare that they have no conflict of interest. 


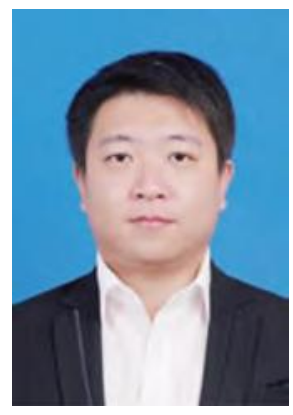

Peng Lv was born in 1985. He received his PhD degree from Jiangsu University in 2014. He later worked the School of Material Science and Engineering, at Jiangsu University, as a research associate. His research focuses on microstructure of material, failure analysis and surface modification.

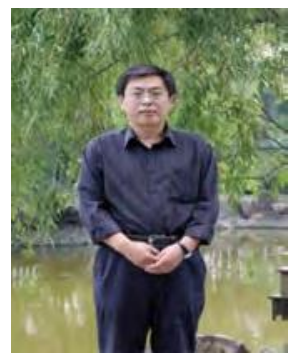

Qingfeng Guan received his MSc degree (1987) from the Institute of Metal Research, Chinese Academy of Sciences and $\mathrm{PhD}$ degree (2006) from Jilin University. During 1987-2005, He worked at Jilin university as a professor. He joined in the School of Material Science and Engineering, Jiangsu University in 2006. His research focuses on the thermal barrier coating material of aircraft engine, microstructure of material and surface modification.

\section{模拟空间环境冷热循环作用下TC4合金的微观结构与性能}

吕鹏 ${ }^{*}$, 徐静博, 杨若然, 张从林, 张福涛, 董书恒, 关庆丰

摘要 本文通过模拟空间环境中冷热循环实验条件, 利用光学显微镜、X射线衍射仪、透射电子显微镜及显微硬度仪分析了低地球轨道冷 热循环作用下TC4钛合金的微观结构状态和性能的演化行为. 实验结果表明, 随着循环次数的增加, 样品的硬度迅速增加到最大值, 在随后 的冷热循环过程中样品出现了循环软化现象; 冷热循环 300 次后, $\alpha$ 和 $\beta$ 相的界面出现大量孔洞, 样品中的典型结构转变为尺寸较大的位错胞 状亚结构, 晶界容易成为应力集中的区域并萌生微裂纹; 500次循环样品中的典型结构为位错胞演化而成的亚晶以及晶内的孪晶和割阶结 构. 本文详细讨论了低地球轨道冷热环境下TC4钛合金微观结构的演变规律和冷热疲劳之间的关系. 